\title{
A novel inhibitor of advanced glycation end-product formation inhibits mesenteric vascular hypertrophy in experimental diabetes
}

\author{
T. Soulis ${ }^{1}$, S. Sastra' , V. Thallas ${ }^{1}$, S. B. Mortensen ${ }^{2}$, M. Wilken², J. T. Clausen ${ }^{2}$, O.J. Bjerrum ${ }^{2}$, H. Petersen ${ }^{2}$, J. Lau ${ }^{2}$, \\ G. Jerums ${ }^{1}$ E. Boel $^{2}$, M.E. Cooper ${ }^{1}$ \\ ${ }^{1}$ Department of Medicine, University of Melbourne, Austin and Repatriation Medical Centre, Heidelberg, Australia \\ ${ }^{2}$ Health Care Discovery, Novo Nordisk, Bagsvaerd, Denmark
}

\section{Abstract}

Aims/hypothesis. Previous studies in our laboratory have shown that the vascular changes in diabetes include hypertrophy of the mesenteric vasculature and that this process can be attenuated by the inhibition of advanced glycation with aminoguanidine. Since aminoguanidine can also act as an inhibitor of nitric oxide synthase, the effect of a novel inhibitor of advanced glycation end-products, formation that does not inhibit nitric oxide synthase, known as 2,3 diaminophenazine (2,3 DAP) was evaluated.

Methods. Initially, in vitro assessment of the ability of 2,3 diaminophenazine to inhibit formation of advanced glycation products was performed. Subsequently, in vivo studies evaluating 2,3 diaminophenazine and aminoguanidine were carried out. Animals were followed for 3 weeks after induction of diabetes and randomised to no treatment, aminoguanidine or 2,3 diaminophenazine. Mesenteric vessels were weighed and advanced glycation end-products were measured by radioimmunoassay in vessel and kidney homogenates. In addition, these products were assessed in mesenteric vessels by immunohistochemistry.

Results. When compared with control animals, diabetes was associated with an increase in mesenteric vascular weight. Treatment of diabetic rats with aminoguanidine or 2,3 diaminophenazine resulted in attenuation of vascular hypertrophy. Both aminoguanidine and 2,3 diaminophenazine reduced the formation of advanced glycation end-products as measured by radioimmunoassay and as assessed immunohistochemically in these vessels. This reduction was also observed in the kidney.

Conclusion/interpretation. These data support the concept that the effects of aminoguanidine in reducing diabetes associated vascular hypertrophy are via inhibition of advanced glycation end-products dependent pathways. [Diabetologia (1999) 42: 472-479]

Keywords Mesenteric arteries, aminoguanidine, advanced glycation end-products, experimental diabetes mellitus.
Extracellular matrix expansion and vascular hypertrophy have been implicated in the pathogenesis of the microvascular complications of diabetes [1]. The

Received: 20 July 1998 and in revised form: 2 November 1998

Corresponding author: T. Soulis, Department of Medicine, Austin and Repatriation Medical Centre, Repatriation Campus, W Heidelberg, Vic, 3081, Australia

Abbreviations: AGEs, Advanced glycation end-products; 2,3 DAP, 2,3 diaminophenazine; CHL, carboxy methyl lysine; AG, aminoguanidine; NO, nitric oxide; $i$ NOS, inducible NO synthase; STZ, streptozotocin; Rnase, ribonuclease. formation of long-lived non-enzymatically glycated proteins has been postulated as a fundamental mechanism in the pathogenesis of these complications [2]. Aminoguanidine (AG) is a hydrazine-like compound which inhibits the formation of advanced glycation end-products (AGEs). This phenomenon has been shown to occur in vivo. Aminoguanidine treatment in humans leads to a reduction in AGE-haemoglobin without influencing the Amadori product, glycated haemoglobin [3]. Aminoguanidine has been shown to retard the development of nephropathy and retinopathy in experimental diabetes $[4,5]$. More recently, it has been shown that aminoguanidine attenuates 
diabetes associated vascular hypertrophy in the mesenteric vascular tree [6]. Aminoguanidine also acts, however, as an inhibitor of nitric oxide synthase [7] and therefore, it has been difficult to determine if its action in experimental diabetes is primarily related to inhibition of AGE formation or to its action as a nitric oxide synthase inhibitor. The advent of 2,3 diaminophenazine (2,3 DAP), which inhibits AGE accumulation without inhibiting inducible nitric oxide synthase (see later), allows us to explore the specific role of inhibition of AGE formation in preventing diabetic vascular complications. This study has evaluated in vitro the effects of 2,3 diaminophenazine, on AGE formation and on the ability of the agent to inhibit inducible nitric oxide synthase ( $i \mathrm{NOs})$. Furthermore, the study has examined the role of the process of advanced glycation in the development of diabetic vascular disease by evaluating the effects of $A G$ as well as the novel inhibitor of glycation, 2,3 DAP, in a model of diabetic vascular disease.

\section{Materials and methods}

Chemical compounds. The synthesis of 2,3-diaminophenazine has been described previously [8]. In brief, o-Phenylenediamine $(5.0 \mathrm{~g})$ dissolved in water $(250 \mathrm{ml})$ was mixed under stirring for $12 \mathrm{~h}$ at $20^{\circ} \mathrm{C}$ with $75 \mathrm{ml}$ ferric chloride $(26 \mathrm{~g}$ anhydrous material in water). The dark violet crystals formed were isolated. After redissolving in water $(125 \mathrm{ml})$ concentrated aqueous ammonia $(25 \mathrm{ml})$ was added and after further addition of water $(125 \mathrm{ml})$ and cooling the crystallized orange product was isolated. Aminoguanidine hydrogen carbonate and diaminoguanidine were purchased from Fluka Chemicals, Buchs, Switzerland.

\section{In vitro studies}

Formation of AGEs on bovine serum albumin. Advanced glycated bovine serum albumin (AGE-BSA) was prepared by in vitro glycation of crystallized and lyophilized BSA (Fraction V, low endotoxin, Sigma Chemicals, St. Louis, Miss, USA) by incubation in the presence of $1 \mathrm{~mol} / 1$ glucose in $0.5 \mathrm{~mol} / 1$ sodium phosphate buffer containing $1 \mathrm{~mol} / \mathrm{l}$ EDTA, $1 \mathrm{~mol} / \mathrm{l}$ phenylmethylsulphonyl fluoride, $1 \mathrm{~mol} / \mathrm{l}$ aprotinin and $1 \mathrm{~mol} / \mathrm{l}$ sodium azide for 120 days. The solution derived was then sterilized by passage through a $0.2 \mu \mathrm{m}$ millipore membrane and the presence of AGEs confirmed by fluorospectrophotometry (excitation $370 \mathrm{~nm}$, emission $440 \mathrm{~nm}$ ) [9]. Extensively AGEmodified BSA was prepared by incubation of BSA, as above, in $500 \mathrm{~mol} / 1$ ribose at $37^{\circ} \mathrm{C}$ in the dark for 90 days in the absence of iron or copper.

Formation of carboxy methyl lysine (CML) on proteins. Carboxy methyl lysine-BSA and CML-collagen were prepared as described previously [10]. Briefly, CML-BSA was prepared using $0.2 \mathrm{~mol} / 1$ phosphate, $\mathrm{pH} 8.0$, as solvent for $1 \mathrm{ml} 175 \mathrm{mg} / \mathrm{ml}$ BSA (Fraction V, Sigma, $175 \mathrm{mg} / \mathrm{ml}$ ) which was simultaneously mixed with $0.5 \mathrm{ml} .0 .3 \mathrm{~mol} / \mathrm{l}$ glyoxylic acid (Sigma) and $0.5 \mathrm{ml}$ freshly prepared $0.9 \mathrm{~mol} / \mathrm{l}$ sodium borohydride $\left(\mathrm{NaBH}_{3} \mathrm{CN}\right)$ (Sigma, Chemicals, Clayton, Australia), and allowed to mix for $10 \mathrm{~min}$ at $37^{\circ} \mathrm{C}$ followed by dialysis against 21 of phosphate buffered saline (PBS) containing $0.1 \%(\mathrm{w} / \mathrm{v}) \mathrm{NaN}_{3}$ overnight at $5^{\circ} \mathrm{C}$. Collagen Type VII $(1 \mathrm{mg} / \mathrm{ml})$, (Sigma, Chemicals, St. Louis, Miss., USA) was suspended in $0.2 \mathrm{~mol} / 1$ phosphate buffer at $\mathrm{pH}$ 8.0. $1556 \mu \mathrm{l}$ of this solution was mixed with $100 \mu \mathrm{l}$ $0.45 \mathrm{~mol} / \mathrm{l}$ glyoxylic acid immediately followed by addition of $330 \mu \mathrm{l} 0.9 \mathrm{~mol} / \mathrm{l} \mathrm{NaBH}_{3} \mathrm{CN}$. The mixture was incubated at $37^{\circ} \mathrm{C}$ for $16 \mathrm{~h}$ followed by dialysis as described above.

The purity of the CML-BSA preparation was assessed by amino acid composition analysis on a modified Beckman 121 MB analyser (Beckman, Fullerton, Calif., USA) after hydrolysis in a closed vial with $6 \mathrm{~mol} / 1 \mathrm{HCl}\left(111^{\circ} \mathrm{C}\right.$ for $\left.24 \mathrm{~h}\right)$. Lysine was the only amino acid residue modified by CML formation. The CML-BSA preparation contained 20 CML-modified lysine residues per molecule albumin corresponding to $34 \%$ of all of the available lysine residues. Agarose gel electrophoresis [11] in $0.1 \mathrm{~mol} / 1$ Tris and $0.038 \mathrm{~mol} / 1$ glycine buffer at $\mathrm{pH} 8.7$, of the CML-BSA preparation, exhibited a faster anodic migration with a normal band width than native BSA, indicating the presence of a homogeneous charge distribution among the AGE-derivatized protein molecules.

Preparation of polyclonal anti-AGE antibodies. New Zealand White rabbits were injected subcutaneously with $50 \mu \mathrm{g}$ of AGE-BSA (which was prepared as described above), emulsified in Freund's Complete Adjuvant, followed by 2 booster injections with $20 \mu \mathrm{g}$ AGE-BSA emulsified in Freunds Incomplete Adjuvant every 2 weeks. The animals were bled 10 days after the last injection and serum was isolated. Protein A affinity purified rabbit IgG was biotinylated by standard methodology.

Preparation of monoclonal AGE antibodies. Mice were immunized by injecting subcutaneously $50 \mu \mathrm{g}$ of AGE-BSA in Freund's Complete Adjuvant followed by two injections with $20 \mu \mathrm{g}$ of AGE in Freunds Incomplete Adjuvant. Highly responsive mice were boosted intravenously with $25 \mu \mathrm{g}$ of prepared AGEs and the spleens were harvested 3 days later. Spleen cells were fused with the myeloma fox cell line as described previously $[12,13]$. Supernatants from derived clones were screened for anti-AGE antibody production in an AGE specific ELISA [14]. A monoclonal antibody, AGE1-2F161, was purified by Protein A affinity chromatography.

Characterization of the polyclonal antibody. The major specificity of the polyclonal antibody for AGE products was found to be the CML-epitope as confirmed by competitive RIA [15]. The AGE-ribonuclease (RNase) constitutes the tracer and standard of the RIA [15]. The amount of AGE present was expressed as ng AGE-RNase equivalents. The minimum detectable dose was $250 \mathrm{ng} / \mathrm{ml}$ and the CV of the assay was $12 \%$ at 2000 ng AGE-RNase [6]. Competition curves were generated using increasing concentrations from $10-1000 \mathrm{ng} / \mathrm{ml}$ of antigens including AGE-BSA, AGE-Rnase, carboxy methyl lysine (CML)-collagen, CML-BSA, free pentosidine (donated from V. Monnier, Cleveland, Ohio, USA), native BSA and native RNase.

Native BSA and RNase did not inhibit tracer binding to the antibody, whereas glycated proteins were shown to produce reproducible inhibition curves. Measured in this way, the antibody recognises several other glycated species including AGE-keyhole limpet haemocyanin and AGE-collagen, and it detects CML modified collagen and CML modified BSA [16]. This indicates that the polyclonal antibody recognises the CML epitope of AGEs [16]. The antibody does not, however, detect pentosidine, an AGE that has been detected in vivo [17].

Assays for estimation of new AGE inhibitor potencies. Characterization of the AGE inhibitor potency of selected test com- 
pounds was done by three in vitro methods. 1) HPLC AGE Fluorescence. The AGE inhibitor potency of selected test compounds was estimated by measuring the formation of fluorescence after 7 days of incubation (at $37^{\circ} \mathrm{C}$ in the dark) of solutions with the following composition: inhibitor compounds at various concentrations, BSA $(10 \mathrm{mg} / \mathrm{ml}$ in sodium phosphate $\mathrm{pH}$ 7.4), ribose (100 mmol/l in sodium phosphate, $\mathrm{pH} 7.4)$. To exclude fluorescence interference from AGE inhibitors, reacted material was separated on a Biosep Sec S3000 size exclusion column $(150 \times 780 \mathrm{~mm}$; Phenomenex, Torrance, Calif., USA $)$. Protein was detected at $280 \mathrm{~nm}$ and AGE fluorescence at 370 $\mathrm{nm} / 470 \mathrm{~nm}$ in a standard flow cell on a Perkin Elmer 5 spectrophotometer (Perkin Elmer, Norwalk, Conn., USA). The fluorescence signal was related to the protein content measured as the absorption at $280 \mathrm{~nm}$. For reasons of comparisons the inhibition of fluorescence was normalized as follows: control sample without added inhibitor was considered to reflect $0 \%$ inhibition. Accordingly complete disappearance of the fluorescence signal corresponded to $100 \%$ inhibition. 2) Incorporation of ${ }^{14} \mathrm{C}$-lysine. The assay for evaluation of AGE formation based on the inhibition of the incorporation of ${ }^{14} \mathrm{C}$-lysine into protein [18] was done on selected test compounds. The composition of the incubations used was identical to those described above for formation of AGEs on bovine serum albumin except that $90 \mathrm{MBq}(2.5 \mu \mathrm{Ci}){ }^{14} \mathrm{C}$-lysine was added per $400 \mu \mathrm{l}$ incubation volume. The amount of incorporated radioactivity was determined by spotting aliquots on filter paper followed by fixation in $5 \%(\mathrm{v} / \mathrm{v})$ trichloroacetic acid that was washed five times and dried before counting in a beta counter. In a similar way to that described above for the fluorescence measurement the radioactivity signal obtained for the control sample without added inhibitor was considered to reflect $0 \%$ inhibition. Accordingly, the radioactivity from a sample without ribose present corresponded to $100 \%$ inhibition. 3) Immunoassay for $A G E$ inhibitor screening. A microtitre based sandwich ELISA was developed for characterization of test compounds with AGE inhibitor activity in a three-step test procedure. The first step in the test was the incubation of BSA and ribose together with various concentrations of the test compound. In each incubation series two extra samples were added as reference: a) BSA and ribose without inhibitor (standard 0) and b) BSA alone (standard 100). The second step was the measurement of the amount of AGE generated by an ELISA technique. A monoclonal antibody, AGE1-2F161, prepared against BSA/ribose AGE, was used as the coating antibody $(5 \mu \mathrm{g} / \mathrm{ml})$ and a polyclonal rabbit antibody, described above, was used as the detecting antibody $(1 \mu \mathrm{g} / \mathrm{ml})$. Phosphate buffered saline $(\mathrm{pH}$ 7.2) with $0.05 \%$ Tween 20 (v/v) was used to wash the ELISA plates and the same buffer with $0.5 \mathrm{~mol} / \mathrm{l} \mathrm{NaCl}$ was used for sample and reagent dilutions. To give a direct measurement of the inhibition resulting from the presence of the test compound, the ELISA was calibrated using serial dilutions. In this way a standard curve giving the relation between per cent inhibition ( $\mathrm{x}$-axis) and response (y-axis) could be determined. The per cent inhibition resulting from a given concentration of test compound was directly calculated from the absorbance of the sample in the ELISA. In the last step, the concentration of the test compound corresponding to $50 \%$ inhibition $\left(\mathrm{IC}_{50}\right)$ was calculated by plotting per cent inhibition against drug concentration (Fig.1).

Assessment of the ability of 2,3-diaminophenazine (NNC390028) to inhibit $N O$ synthase. In vitro studies were carried out to determine if 2,3 DAP inhibited inducible NO synthase [19, 20]. This was assessed by measuring the conversion of ${ }^{14} \mathrm{C}$-arginine to ${ }^{14} \mathrm{C}$-citrulline [20]. In brief, RAW (264.7) cell extracts were used as a source of inducible NO synthase [21]. Cell ex-
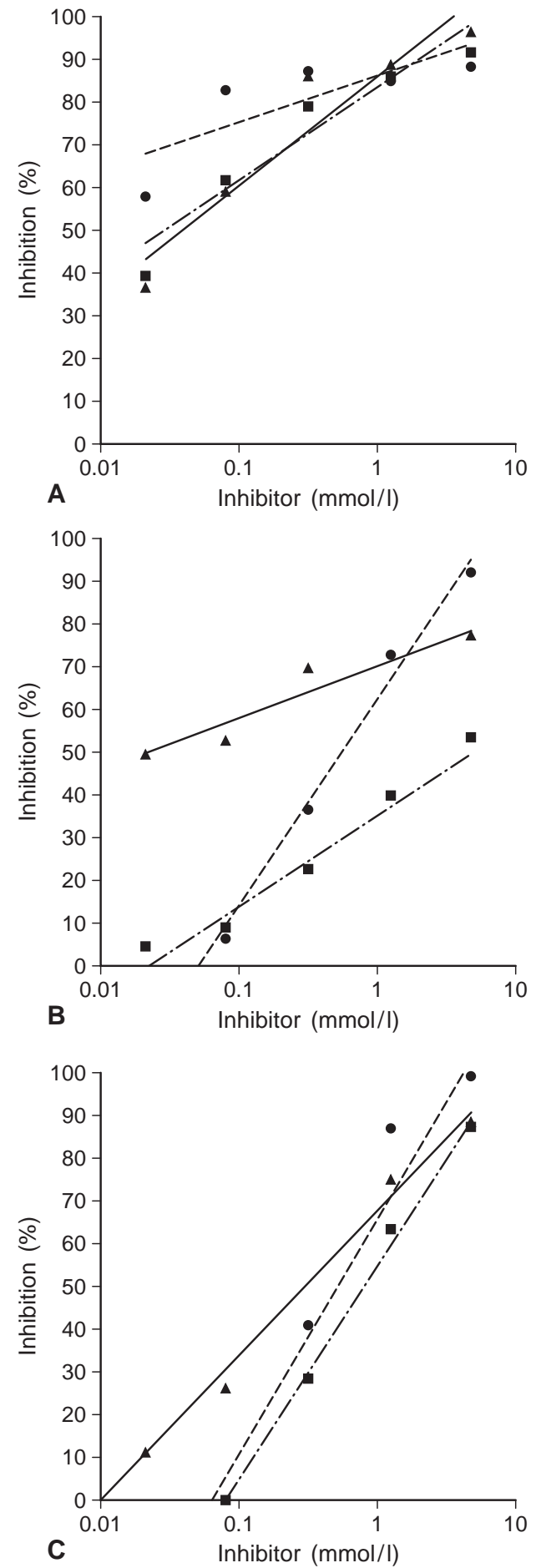

Fig.1 A-C. The potency of inhibitors of AGE formation in vitro on a model system of BSA incubated with ribose is compared in these graphs A 2,3 DAP, B aminoguanidine and $\mathbf{C}$ diaminoguanidine. For each compound the inhibitor concentrations in $\mathrm{mmol} / \mathrm{l}$ used in the incubations are shown on the $\mathrm{x}$ axis, whereas the y-axis indicates the per cent inhibition of AGE formation compared with incubation without inhibitor added ( $0 \%$ inhibition) and without ribose added (100\% inhibition). "Elisa" denotes detection of formed AGE with antibodies: " "14-Lys" ( $\boldsymbol{\Delta}$ ) describes AGE formation as described by ${ }^{14} \mathrm{C}$-Lysine incorporation into proteins and $\square$ "Flu HPLC" ( $\square$ ) describes AGE detection by fluorescence after HPLC fractionation of reactants (for experimental details see Materials and methods) 
tracts were incubated with ${ }^{14} \mathrm{C}$-arginine for $1 \mathrm{~h}$ at $37^{\circ} \mathrm{C}$. The generated ${ }^{14} \mathrm{C}$-citrulline was rescued from the media after addition of the cation exchanger resin, AGVX8 (200-400 mesh, Biorad, Richmond, Calif., USA) and subsequent filtration. The radioactivity in the range of 1000-20 $000 \mathrm{dpm}$ was measured on a Packard beta counter (Packard Instrument Company, Meriden, Conn., USA). The final inhibitor concentrations in the extract were in the range of $0.004 \mathrm{mmol} / 1$ to $8 \mathrm{mmol} / \mathrm{l}$. To further assess the degree of $i$ NOs inhibition, nitrite production by the cells was measured using the Griess reagent (Sigma) [19].

\section{In vivo studies}

Male Sprague Dawley rats aged 8 weeks, weighing between 200 and $250 \mathrm{~g}$ were randomized to receive streptozotocin (STZ) at a dose of $45 \mathrm{mg} / \mathrm{kg}$ (diabetic) or citrate buffer alone (control). Animals were then further randomized to receive either no treatment, AG in drinking water (diabetic dose, $1 \mathrm{~g} / \mathrm{l}$; control dose, $2 \mathrm{~g} / \mathrm{l}$ ) [4] or the AGE inhibitor 2,3 DAP (diabetic dose, $20 \mathrm{mg} / \mathrm{kg}$ body weight/day in drinking water; control dose, $40 \mathrm{mg} / \mathrm{kg}$ body weight/day in drinking water). All animals were given free access to standard chow containing $20 \%$ protein (Clark, King, Melbourne, Australia). Only STZ-treated animals with plasma glucose concentrations higher than $15 \mathrm{mmol} / \mathrm{l} 1$ week after induction of diabetes were considered diabetic and included in the study. All diabetic animals received 4 units insulin zinc suspension (Ultratard HM, Novo Nordisk, Bagsvaerd, Denmark) injected subcutaneously three times a week to maintain body weight and improve survival. Animals were killed at 3 weeks of age.

Immediately before killing, rats were weighed and systolic blood pressure was determined by tail cuff plethysmography [22]. Animals were killed by decapitation and blood collected for determination of plasma glucose by a glucose oxidase technique and glycated haemoglobin $\left(\mathrm{HbA}_{1 \mathrm{c}}\right)$ by HPLC (Biorad). Food and water intake were assessed weekly in animals which had been placed in individual metabolic cages (Iffa Credo, L'Arbresesle, France). The mesenteric vessels were then removed and stripped of surrounding fat, connective tissue and veins to yield the superior mesenteric arterial tree as described previously [6]. The vessels were weighed in liquid nitrogen and subsequently stored at $-80^{\circ} \mathrm{C}$.

Radioimmunoassay for quantification of AGE in mesenteric vessels. Tissue homogenates from both mesenteric vessels and kidney were obtained from a subset of animals studied at 3 weeks and assayed for AGEs by RIA, as carried out previously in our laboratory [15]. The antibody used in this assay was directed against advanced glycated bovine serum albumin (BSA) as described above. An AGE-RNase was used for preparation of tracer and standards. The AGE-RNase was iodinated using lacto-peroxidase [23] and the AGE-RNase standards were generated as a result of 6 months incubation of RNase with $0.5 \mathrm{~mol} / 1$ glucose in $0.2 \mathrm{~mol} / 1$ phosphate buffer $\mathrm{pH} 7.2$ at $37^{\circ} \mathrm{C}$. Collagenase extracted mesenteric vessel homogenates were incubated with the AGE-BSA antibody and tracer for $5 \mathrm{~h}$ at room temperature [6]. Sheep anti-rabbit $\mathrm{IgG}$ was then added and incubated overnight at room temperature. Precipitation of proteins was carried out by addition of $8 \%$ polyethylene glycol 6000. The minimum concentration of AGE-RNase detectable was $250 \mathrm{ng} / \mathrm{ml}$ protein and the $\mathrm{CV}$ of this assay was $11.9 \%, n=4$ at a concentration of $2 \mu \mathrm{g}$ AGE-RNase/mg protein. The standard curve was generated with serial AGERNase dilutions. Radioactivity was measured using a gamma counter (Canberra Packard Instruments, St. Louis, Mo.,
USA) and the amount of AGEs present was expressed as equivalents of ng AGE-RNase.

Assessment of AGE levels in vessels by immunohistochemistry. To complement the results obtained by RIA and to localise AGE accumulation within tissues, AGE staining of tissues was assessed by an immunoperoxidase technique using the polyclonal anti-AGE antibody described previously which detects CML-containing proteins but not pentosidine [6]. Formalin-fixed paraffin embedded sections $(4 \mu \mathrm{m})$ of the mesenteric vessels were cut, placed on gelatinized slides, rehydrated and treated with $1 \% \mathrm{H}_{2} \mathrm{O}_{2} /$ methanol followed by incubation in Protein Blocking Agent (Lipshaw-Immunon, Pittsburgh, Pa., USA) for $20 \mathrm{~min}$ at room temperature. Sections were then incubated with the anti-AGE antibody for $30 \mathrm{~min}$ at room temperature, washed in PBS and incubated with biotinylated swine anti-goat, mouse, rabbit immunoglobulin (DAKO, Carpinteria, Calif., USA) and peroxidaseconjugated streptavidin (DAKO). Peroxidase conjugates were subsequently localized using diaminobenzidine tetrahydrochloride as a chromogen. As a control for anti-AGE immunoreactivity, AGEs formed in vitro, as described above were preincubated with anti-AGE antibody and used in place of the AGE antibody alone in the normal staining procedure. Tissues treated in this manner showed no positive staining [24].

\section{Statistics}

All data are shown as means \pm SEM. Data were analysed by ANOVA using the StatView II program (Abacus Concepts, Berkeley, Calif., USA) on a Macintosh personal computer (Apple, Cupertino, Calif., USA). Comparisons between group means were analysed by Fisher's least significant difference method. A $p$ value of less than 0.05 was considered statistically significant.

\section{Results}

In vitro characterisation of $A G E$ inhibitors: $A G E$ inhibition. A number of chemical compounds were selected for characterisation of their ability to inhibit AGE formation in the three test systems used, as described in Materials and methods. On the basis of the inhibitory effect observed in these three assays one compound 2,3 DAP was selected for further studies. As shown by the inhibitor curves in Figure 1A the in vitro effects of 2,3 DAP measured by HPLC-fluorescence or ${ }^{14} \mathrm{C}$-lysine incorporation were very similar yielding $\mathrm{IC}_{50}$ values in the range of 30-40 $\mu \mathrm{mol} / \mathrm{l}$. The $\mathrm{IC}_{50}$ obtained by the ELISA technique was less than $10 \mu \mathrm{mol} / \mathrm{l}$. The $\mathrm{IC}_{50}$ values obtained with aminoguanidine by HPLC-fluorescence and ${ }^{14} \mathrm{C}$-Lysine incorporation varied from $0.02 \mathrm{mmol} / \mathrm{l}$ to $4 \mathrm{mmol} / \mathrm{l}$ whereas the ELISA results for AG were approximately $0.5 \mathrm{mmol} / \mathrm{l}$ (Fig.1B). Diaminoguanidine also inhibited AGE formation, as assessed by the three different techniques. The $\mathrm{IC}_{50}$ for diaminoguanidine was similar to $A G$ and was less than $1 \mathrm{mmol} / 1$ (Fig. 1C). 
Table 1. Clinical characteristics

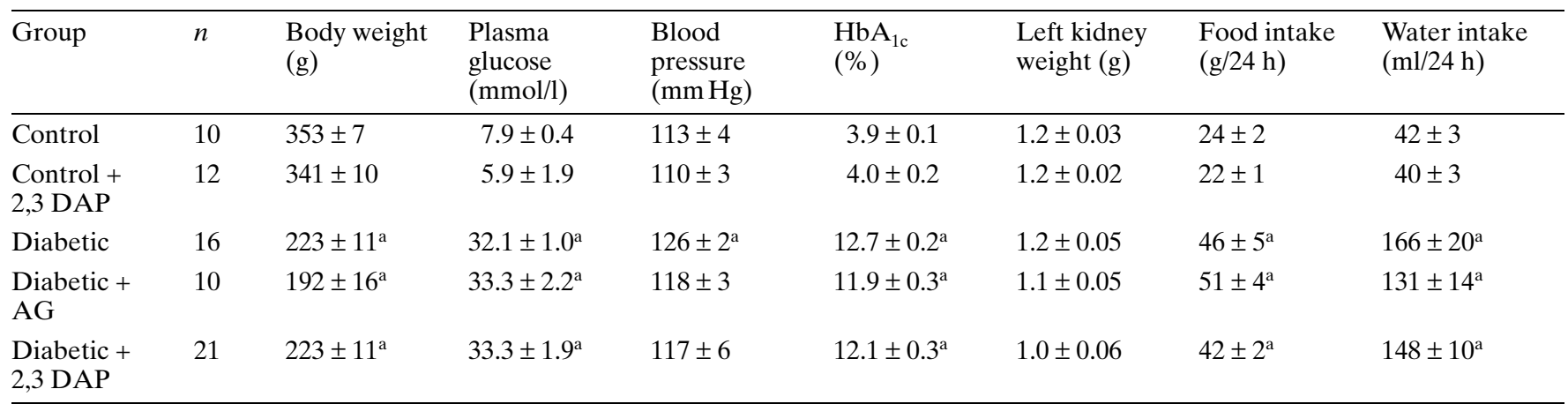

Data are shown as means \pm SEM. ${ }^{\mathrm{a}} \mathrm{p}<0.01$ vs control

In vitro characterisation of AGE inhibitors: iNOs inhibition. The effect of 2,3-diaminophenazine on $i$ NOS was examined and compared with $\mathrm{AG}$ by evaluating the conversion of ${ }^{14} \mathrm{C}$-arginine to ${ }^{14} \mathrm{C}$-citrulline. The $\mathrm{IC}_{50}$ for inhibition of inducible NO synthase for 2,3 DAP and AG were $0.5 \mathrm{mmol} / 1$ and $0.015 \mathrm{mmol} / \mathrm{l}$, respectively. This represents a 33 -fold

Fig. 2 A-D. Mesenteric vessel weight. B Advanced glycation end-products (expressed as ngAGE-RNase/ml) in mesenteric vessels. C Glomeruli. D Renal tubules. All are shown as means \pm SEM. $* p<0.01$ vs $\mathrm{C} ; \dagger p<0.01$ vs $\mathrm{D} ; * * p<0.05$ vs $\mathrm{D}+\mathrm{AG}$. C, control; D, diabetic
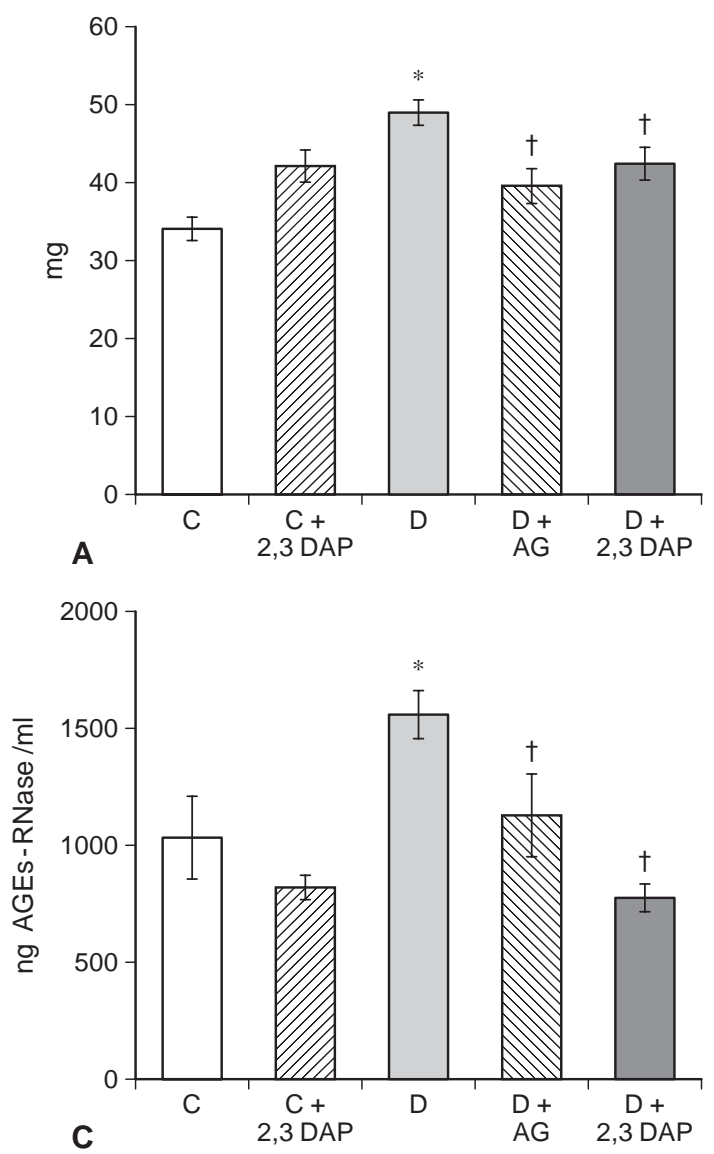

difference in inhibitory potency between the two compounds. In addition, 2,3 DAP only inhibited $i \mathrm{NOs}$, as assessed by a $50 \%$ reduction in nitrite production $\left(\mathrm{IC}_{50}\right)$, at concentrations greater than $5 \mathrm{mmol} / \mathrm{l}$.

Clinical variables. Table 1 depicts various biochemical variables from each of the different groups examined. Diabetes was associated with reduced body weight compared with control rats. The treatment of diabetic rats with $\mathrm{AG}$ and 2,3 DAP did not influence body weight. Treatment of control rats with 2,3 DAP did not affect body weight. Plasma glucose concentrations and $\mathrm{HbA}_{1 \mathrm{c}}$ were raised in diabetic animals com-
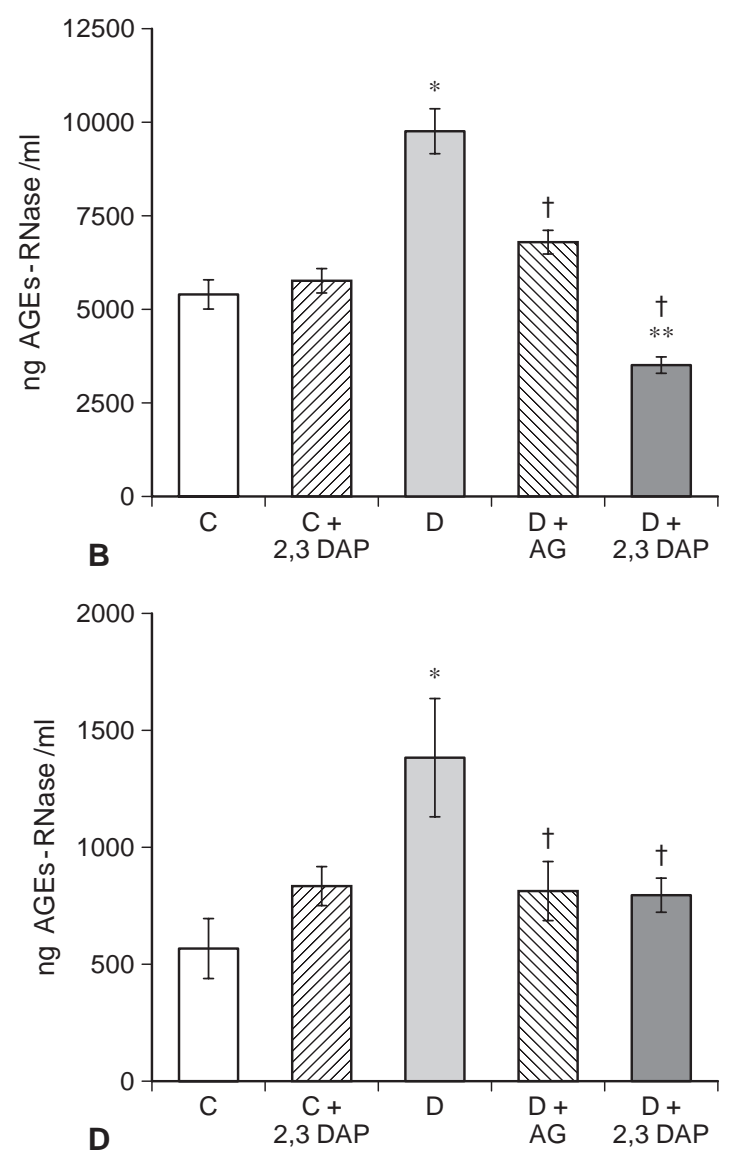
A Control

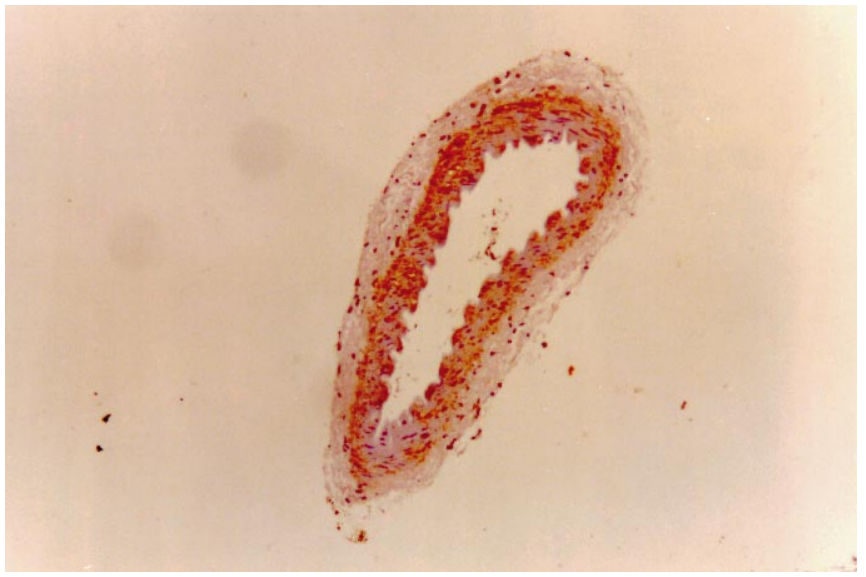

C Diabetic + AG

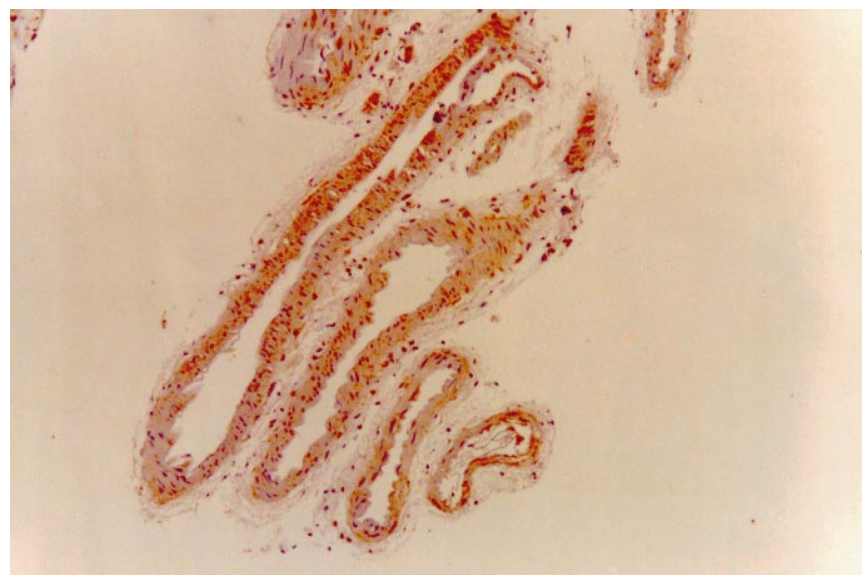

Fig. 3 A-D. Immunohistochemical staining for advanced glycation end-products in mesenteric blood vessels from (A) Control, (B) Diabetic, $(\mathbf{C})$ Diabetic + AG and (D) Diabetic + 2,3 DAP rats. Magnification $\times 40$

pared with control animals. Treatment of both control and diabetic rats with AG or 2,3 DAP did not influence glycaemic control. There was a modest increase in blood pressure in diabetic rats which was not observed in rats treated with AG or 2,3 DAP. Diabetic rats had increased food and water intake compared with control animals. Food and water intake were not affected by treatment with AG or 2,3 DAP.

After 3 weeks of diabetes, mesenteric vessel weight was increased in diabetic rats compared with control rats. Treatment of diabetic rats with AG or 2,3 DAP attenuated mesenteric vessel weight towards values observed in control rats (Fig. 2A). Mesenteric vessel weight in control rats was not influenced by 2,3 DAP.

Advanced glycation end-product radioimmunoassay. Levels of AGE, as measured by radioimmunoassay, in mesenteric vessels and kidney at the end of the 3week experimental period are shown in Figure 3. Di-
B Diabetic

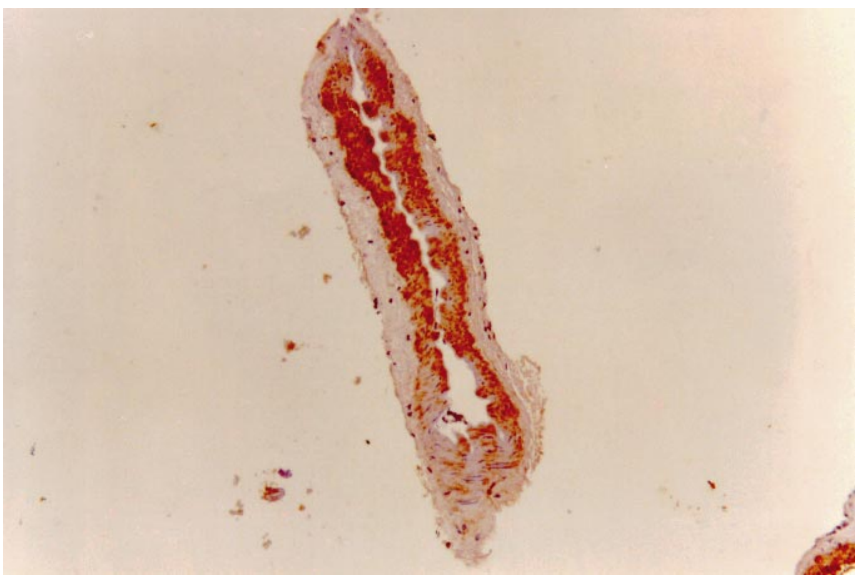

D Diabetic + 2,3 DAP

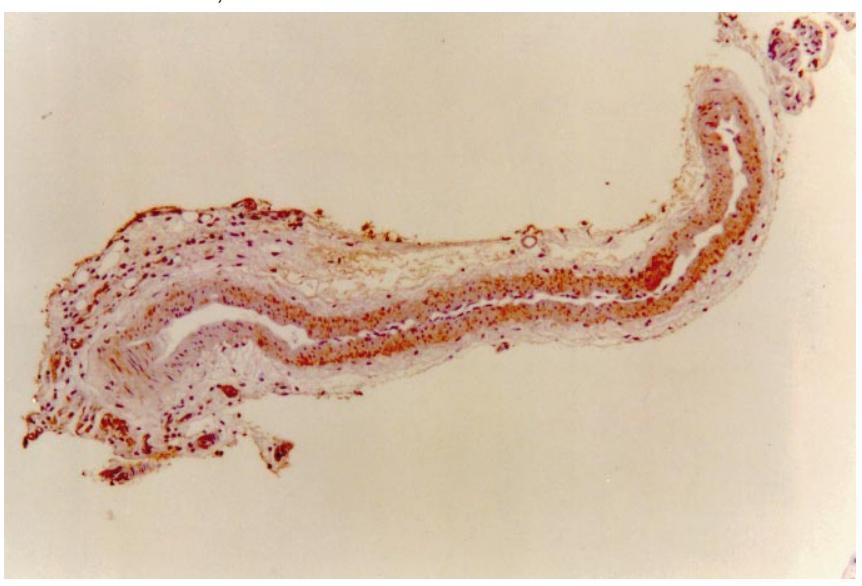

abetes was associated with increased AGEs in mesenteric vessels (Fig. 2B), glomeruli (Fig. 2C) and renal tubules (Fig. 2D) compared with control animals. Treatment of diabetic rats with AG or 2,3 DAP reduced mesenteric and renal AGEs to levels similar to those observed in control rats. Levels of AGE were not influenced by 2,3 DAP in control rats at any of the sites evaluated.

Advanced glycation end-product staining. Mesenteric blood vessels and kidney were stained at 3 weeks for AGEs. These were localised to the medial layer of blood vessels (Fig.3). There appeared to be more AGEs present after 3 weeks of diabetes in the media of mesenteric vessels. Treatment of diabetic animals with AG or 2,3 DAP for 3 weeks reduced the amount of AGEs present in blood vessels (Fig. 3).

\section{Discussion}

This study explored the role of 2,3 DAP as an inhibitor of AGE accumulation. In vitro studies clearly documented inhibition of AGE formation, as assessed by a range of different methods. In addition, this compound inhibited AGE accumulation in vivo 
in both blood vessels and the kidney, as assessed by RIA and by immunohistochemistry. Finally, 2,3 DAP was compared with aminoguanidine in inhibiting an AGE-dependent process, the development of diabetes associated mesenteric vascular hypertrophy [6]. Indeed, 2,3 DAP was as effective as AG in attenuating vascular hypertrophy, consistent with the previously postulated view that the actions of $A G$ on vascular growth are through AGE-dependent pathways.

It has been suggested previously that some of the actions of AG could be due to this drug's ability to inhibit the various nitric oxide synthases and in particular the inducible isoform [7]. In our study, 2,3-diaminophenazine did not, however, inhibit inducible NO synthase, as measured by two different approaches. Firstly, by assessment of the conversion of arginine to citrulline, there was a 33-fold superiority in the ability of AG compared with 2,3 DAP to inhibit $i$ NOs in vitro. This difference needs to be considered in the context of the in vivo studies where the dose of AG given was 50-fold higher than the dose of 2,3 DAP. Secondly, by measuring nitrite formation in RAW cells 2,3 DAP only inhibited iNOS at very high concentrations of milimoles concentrations $\left(\mathrm{IC}_{50}>5 \mathrm{mmol} / \mathrm{l}\right)$. By contrast, $\mathrm{AG}$ is a more potent inhibitor of iNOS with an $\mathrm{IC}_{50}$ of $170 \mu \mathrm{mol} / \mathrm{l}$ [25]. Further evidence that the effect of AG on vascular hypertrophy is due to inhibition of AGE accumulation is suggested by a previous study which showed that $\mathrm{N}^{\mathrm{G}}$-nitro-L-arginine methyl ester (L-NAME), a compound which inhibits all NO synthases, does not reproduce this effect of AG on vascular structure [26].

The compound, 2,3 DAP was selected on the basis of a screening procedure, using three different methods. The criterion for selection was the observation of an inhibitory effect with all three methods having $\mathrm{IC}_{50}$ values better or similar to the known AGE inhibitor, AG. Based on both in vitro and in vivo studies, 2,3 DAP is a powerful inhibitor of AGE accumulation, possibly even more potent than AG. In vitro studies using ${ }^{14} \mathrm{C}$-lysine incorporation and HPLC AGE fluorescence suggested superiority of 2,3 DAP over AG in preventing AGE formation. In the in vivo studies, a similar pattern emerged with less AGE accumulation in mesenteric vessels with 2,3 DAP compared with AG. Therefore, 2,3 DAP could be a preferred molecule for assessment of the specific role of AGE accumulation in the pathogenesis of diabetic complications. Firstly, it is at least as potent as $A G$ in preventing AGE formation and secondly, in contrast to AG, it does not have potent inhibitory effects on inducible NO synthase.

Our study confirmed that there was an increase in AGE in mesenteric vessels and in glomeruli and renal tubules from diabetic rats. In blood vessels, the major site of AGE accumulation appears to be in the medial layer, as shown previously by our group $[6,24]$. The compound 2,3 DAP was at least as effective as AG in reducing AGE accumulation in these vessels and immunohistochemical studies showed that this effect of 2,3 DAP on AGE accumulation in vivo was not confined to blood vessels but was also observed in the kidney (data not shown). As observed previously by our group and others, diabetes is associated with AGE accumulation both in renal tubules and glomeruli $[16,27]$. It remains to be determined if 2,3 DAP will also confer protection at the major sites of microvascular complications in diabetes such as the kidney, retina and peripheral nerves as previously shown for $\mathrm{AG}[4,5,28]$.

There was a modest increase in blood pressure in diabetic rats shortly after induction of diabetes, which, as has been observed previously by our group, is attenuated by AG [26]. This action of AG is unexplained but might be related to the ability of this agent to prevent AGE accumulation. It has been reported that AGEs quench NO [29] and this could lead to a rise in blood pressure which would be attenuated by agents which prevent AGE accumulation in blood vessels. Indeed, the ability of 2,3 DAP to also prevent this rise in blood pressure is consistent with the view that this involves effects of both $A G$ and 2,3 DAP on AGE-dependent pathways.

The multiple actions of AG include effects not only on AGE formation and NO synthesis but also on diamine oxidase [30]. Furthermore, it cannot be excluded that other pathways, in addition to advanced glycation, could be inhibited by 2,3 DAP. These include effects on lipid peroxidation and chelation of redoxactive metals [31]. Previous studies by our group have failed to document a statistically significant effect of AG on the generation of thiobarbituric acid reactive substances, a relatively crude marker of peroxidation, or on plasma cholesterol concentrations [32]. These pathways were not directly evaluated in the present study. The possibility that AG has multiple actions has made it difficult for investigators to determine the relative roles of the various biochemical pathways that are modulated by AG therapy in the genesis of diabetic vascular complications and in mediating the protective effects of $\mathrm{AG}$ on experimental diabetic retinopathy and nephropathy. More potent inhibitors of advanced glycation such as ALT 462 and ALT 486 have also been developed recently [33]. Their long-term effects in vivo on diabetic complications have not, however, been fully determined.

\section{References}

1. Williamson JR, Tilton RG, Chang K, Kilo C (1988) Basement membrane abnormalities in diabetes mellitus: relationship to clinical microangiopathy. Diabetes Metab Rev 4: $339-370$ 
2. Cerami A, Vlassara H, Brownlee M (1988) Role of advanced glycosylation products in complications of diabetes. Diabetes Care 1: 73-79

3. Makita Z, Vlassara H, Rayfield E et al. (1992) Hemoglobin-AGE: a circulating marker of advanced glycosylation. Science 258: 651-653

4. Soulis-Liparota T, Cooper M, Papazoglou D, Clarke B, Jerums G (1991) Retardation by aminoguanidine of development of albuminuria, mesangial expansion, and tissue fluorescence in streptozocin-induced diabetic rat. Diabetes 40: 1328-1334

5. Hammes H, Martin S, Federlin K, Geisen K, Brownlee M (1991) Aminoguanidine treatment inhibits the development of experimental diabetic retinopathy. Proc Natl Acad Sci USA 88: 11555-11558

6. Rumble JR, Cooper ME, Soulis T et al. (1997) Vascular hypertrophy in experimental diabetes: role of advanced glycation end products. J Clin Invest 99: 1016-1027

7. Corbett JA, Tilton RG, Chang K et al. (1992) Aminoguanidine, a novel inhibitor of nitric oxide formation, prevents diabetic vascular dysfunction. Diabetes 41: 552-556

8. Manassen J, Kalif S (1966) Organic Polymers. Correlation between Their Structure and Catalytic Activity in Heterogeneous Systems. II. Models for Dehydrogenation Catalysts. J Am Chem Soc 88: 1943-1947

9. Monnier V, Vishwanath V, Frank K, Elmets G, Dauchot P, Kohn R (1986) Relation between complications of type I diabetes mellitus and collagen-linked fluorescence. $\mathrm{N}$ Engl J Med 314: 403-408

10. Reddy S, Bichler J, Wells KK, Thorpe SR, Baynes JW (1995) N epsilon-(carboxymethyl)lysine is a dominant advanced glycation end product (AGE) antigen in tissue proteins. Biochemistry 34: 10872-10878

11. Bjerrum OJ, Inglid A, Lowenstein H, Weeke B (1973) Quantitation of human IgG by rocket immunoelectrophoresis at pH5.0 by use of caramylated antibodies: a routine laboratory method. Clin Chim Acta 46: 337-343

12. Kohler G, Milstein C (1976) Derivation of specific antibody-producing tissue culture and tumour lines by cell fusion. Eur J Immunol 6: 511-519

13. Taggart RT, Samloff IM (1983) Stable antibody-producing murine hybridomas. Science 219: 1228-1230

14. Makita Z, Vlassara H, Cerami A, Bucala R (1992) Immunochemical detection of advanced glycosylation end products in vivo. J Biol Chem 267: 5133-5138

15. Soulis T, Cooper ME, Vranes D, Bucala R, Jerums G (1996) The effects of aminoguanidine in preventing experimental diabetic nephropathy are related to duration of treatment. Kidney Int 50: 627-634

16. Soulis T, Cooper ME, Sastra S et al. (1997) Relative contributions of advanced glycation and nitric oxide synthase inhibition to aminoguanidine-mediated renoprotection in diabetic rats. Diabetologia 40: 1141-1151

17. Sell DR, Lapolla A, Odetti P, Fogarty J, Monnier VM (1992) Pentosidine formation in skin correlates with severity of complications in individuals with long-standing IDDM. Diabetes 41: 1286-1292

18. Prabhakaram M, Ortwerth B (1994) Determination of glycation cross-linking by the sugar-dependent incorporation of (C-14) lysine into protein. Anal Biochem 216: 305-312
19. Karlsen AE, Andersen HU, Vissing H et al. (1995) Cloning and expression of cytokine-inducible nitric oxide synthase cDNA from rat islets of Langerhans. Diabetes 44: 753-758

20. Bredt DS, Snyder SH (1989) Nitric oxide mediates glutamate-linked enhancement of cGMP levels in the cerebellum. Proc Natl Acad Sci USA 86: 9030-9033

21. Amin AR, Attur MG, Thakker GD et al. (1996) A novel mechanism of action of tetracyclines - effects on nitric oxide synthases. Proc Natl Acad Sci USA 93: 14014-14019

22. Bunag R (1973) Validation in awake rats of a tail-cuff method for measuring systolic pressure. J Appl Physiol 34: 279-282

23. Salacinski P, McLean C, Sykes J, Clement-Jones W, Lowry $P$ (1981) Iodination of proteins, glycoproteins and peptides using a solid phase oxidising agent, 1,3,4,6-1,3,4,6tetrachloro-3 a,6a-diphenylglycoluril. Anal Biochem 117: 136-146

24. Soulis T, Thallas V, Youssef S et al. (1997) Advanced glycation end products and the receptor for advanced glycated end products co-localise in organs susceptible to diabetic microvascular injury: immunohistochemical studies. Diabetologia 40: 619-628

25. Nakane M, Pollock JS, Klinghofer V et al. (1995) Functional expression of three isoforms of human nitric oxide synthase in baculovirus-infected insect cells. Biochem Biophys Res Commun 206: 511-517

26. Rumble J, Komers R, Cooper M (1995) Kinins or nitric oxide, or both, are involved in the antitropic effects of angiotensin converting enzyme inhibitors on diabetes-associated mesenteric vascular hypertrophy in the rat. J Hypertens 14: 601-607

27. Shikata K, Makino H, Sugimoto H et al. (1995) Localization of advanced glycation endproducts in the kidney of experimental diabetic rats. J Diabetes Complications 9: 269-271

28. Kihara M, Schmelzer JD, Poduslo JF, Curran GL, Nickander KK, Low PA (1991) Aminoguanidine effects on nerve blood flow, vascular permeability, electrophysiology, and oxygen free radicals. Proc Natl Acad Sci USA 88: 6107-6111

29. Hogan M, Cerami A, Bucala R (1992) Advanced glycosylation endproducts block the antiproliferative effect of nitric oxide. Role in the vascular and renal complications of diabetes mellitus. J Clin Invest 90: 1110-1115

30. Brownlee M (1994) Lilly Lecture 1993. Glycation and diabetic complications. Diabetes 43: 836-841

31. Cameron NE, Cotter MA (1995) Neurovascular dysfunction in diabetic rats - potential contribution of autoxidation and free radicals examined using transition metal chelating agents. J Clin Invest 96: 1159-1163

32. Soulis-Liparota T, Cooper ME, Dunlop M, Jerums G (1995) The relative roles of advanced glycation, oxidation and aldose reductase inhibition in the development of experimental diabetic nephropathy in the Sprague-Dawley rat. Diabetologia 38: 387-394

33. Kochakian M, Manjula BN, Egan JJ (1996) Chronic dosing with aminoguanidine and novel advanced glycosylation end product formation inhibitors ameliorates cross-linking of tail tendon collagen in streptozotocin-induced diabetic rats. Diabetes 45: 1694-1700 